\title{
A taxonomic proposal for multiliteracies and their competences
}

\author{
Miguel-Ángel Marzal
}

Nota: Este artículo se puede leer en español en:

http://www.elprofesionaldelainformacion.com/contenidos/2020/jul/marzal_es.pdf

How to cite this article:

Marzal, Miguel-Ángel (2020). "A taxonomic proposal for multiliteracies and their competences". Profesional de la información, v. 29, n. 4, e290435.

https://doi.org/10.3145/epi.2020.jul.35

Manuscript received on $12^{\text {th }}$ November 2019 Accepted on $24^{\text {th }}$ February 2020

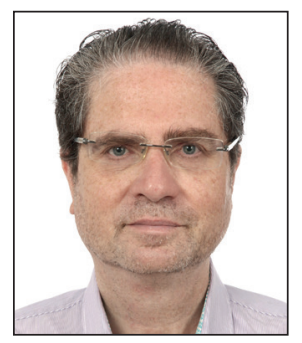

\author{
Miguel-Ángel Marzal \\ https://orcid.org/0000-0003-2039-234X \\ Universidad Carlos III de Madrid \\ Facultad de Humanidades, Comunicación y \\ Documentación \\ Madrid, 126. 28903 Getafe (Madrid), Spain \\ mmarzal@bib.uc3m.es
}

\begin{abstract}
The aim of this study is to analyze information and communication competences and their alphabets, both of which are necessary for effective knowledge-based content management. The evolution of the associated specialties or techniques, i.e., literacies, which have emerged to address this task more effectively are considered. The hypothesis that a taxonomic model can be used to order and coordinate literacies, in combination with an application metamodel within the framework of the Voremetur research project, was investigated. The methodology used to complete this analysis adopts an evolutionary approach comprising: (1) a first divergent phase describing the era of literacies and multiple literacies, in which field-specific competences and tools prevail; (2) a second convergent phase of information and digital literacy, whose associated competences become the targets of knowledge; and (3) a third divergent phase, based on multiliteracies, as a consequence of Big Data and its effects, to address which data literacy, together with "digital competences," emerged as new and complex ways of processing web content. Based on this premise, the classifications introduced by Bawden, Stordy, Secker \& Coonan, and Mackey \& Jacobson are proposed as a taxonomic model, using the metamodel definition from the Voremetur project. This results in the proposal of a multiliteracy including implementations that range from visual literacy and new media literacy, strategies for the selection of keywords as taxonomic labels, semantic control to define taxonomic categories, to a metamodel definition based on the categories obtained in the taxonomy. The development of the metamodel is presented through a program oriented at higher education within the framework of academic literacy, as a means for incorporation into curricula, including a definition of its paradigmatic and conceptual framework, the factors relevant to its programming and instructional design, educommunication as a didactic methodology approach, and digital educational objects as didactic materials, followed by an appropriate evaluation.
\end{abstract}

\section{Keywords}

Metaliteracy; Information literacy; Visual literacy; New media literacy; Taxonomies; Taxonomic models; Multiliteracies; Higher education; Classification; Voremetur.

Funding

This article is a result of the project "Vocabularies for a Network of Media Art Archives and Collections and its effects: Metaliteracy and Knowledge Tourism" (HAR2016-75949-C2-1-R) funded by the Ministry of Economy and Competitiveness of Spain. 


\section{Introduction}

During the second half of the 20th century, the well-known development of mass media heralded the arrival and increasing impact of so-called new information and communication technologies, definitively altering the Gutenberg Galaxy and its associated reading-writing modes and forms of communication, thereby transforming the behavior of people when faced with news and information, as well as learning of knowledge and wisdom. As these effects extended and became factors determining social cohesion, together with the threat of the digital divide and a new economic model (digital and knowledge economy), social and political agents had to turn this phenomenon from a threat into an opportunity by devising the principles of an information policy.

To develop such a policy, early scholars and specialists suggested the need to generate "another" alphabet to read and write in such new technological environments with their own codes, viz. a "literacy" capable of capturing and communicating content. It is significant that, in trying to respond to this challenge, those working on different cases and various researchers converged on the need to considered what "literacy" should be, surpassing the traditional means of acquiring reading, writing, and calculation ability. This development was motivated by the declaration of 1990 as the International Literacy Year by the United Nations (UN). This definition of literacy from a "functional" perspective provided a very clear notion of its evolution towards behaviors and abstract discursive capacities.

A professional, academic, and scientific journey thus began regarding the value of literacy in new digital spaces, finally arriving at the question of how many literacies are necessary for the knowledge society, which forms the hypothesis of this work.

The aim of the present study is not to describe and analyze new literacies as specialties in themselves, or their objects, aims, and methods, but rather to provide a complete overview of such efforts as a response to the development of certain competences in these new environments. In principle, it aims to analyze the chronology of the appearance and application of different literacies. This is a question of identifying a common foundation and the links therein to provide an order for the sake of greater efficiency. In order to analyze the present situation and work towards the generation of a "taxonomy," it therefore appears appropriate to adopt an evolutionary based on the labeling of the phases and the reasons that explain their diversity.

\section{From literacies to multiliteracies}

A review of the scientific literature reveals that, since the start of the century, a significant number of studies on metrics and altmetrics have been published. The consultation of databases and networks and the application of bibliometric and scientometric methods enable the collection of the terms for periods, places, and entities most widely used by authors to denote this emerging literacy, which requires other skills and environments for its use and application (Pinto; Cordón; Gómez-Díaz, 2010). The results are very significant: On the one hand, there is an extended list of such terms and keywords, occurring with a frequency that varies depending on the variable considered, but always exhibiting a marked tendency towards atomization; on the other hand, each term is usually accompanied, albeit to different degrees, with greater fragmentation in terms of the description of skills, abilities, or competences. The correspondence between English and other languages, such as Spanish, further complicates this issue.

The result is that, for many professionals who need to design and develop a competency program for the new literacy in their field, the perception is one of chaos, or at least a very unstable balance, when planning a training and educational policy and strategy. This panorama explains why, among scholars, ways of constituting a conceptual "order" have begun to be studied in order to enable more efficient applications. The starting point is undoubtedly provided by the excellent classic study by Bawden (2002), which provides the perspective on which the following chronology is based.

\subsection{Literacies and multiple literacies}

In this initial stage, formulated in 1974 by Zurkowski, whose defining elements derive from the notion of functional literacy, literacy referred to the mastery of abilities regarding concrete objectives, methods, and application objects (Snavely; Cooper, 1997). This perspective implied a fragmentation due to the emergence of concepts such as health, agricultural, legal, and labor literacies as well as many others, with as many literacies as application objects, as well as a "localist" specificity and a clear limitation of aims and value. The 1980 s was the era of literacies. 
The ecosystem of these literacies would be permanently altered by the development and impact of ICT and the Internet. This resulted in a qualitative leap in which the object, with its associated methods and objectives, no longer determined the literacy. Rather, priority was given to the development of capacities for an efficient use of tools to support knowledge and a multiple and multiplying use of what was learned. The New London Group pointed out how such new electronic supports and digital documents (hypertexts, hypermedia) enabled a multifaceted and multisequential narration of their content, thus requiring digital reading competences so that the user/ reader could read them based on "situated knowledge" (interpretation), "instructional design" (understanding of argumentation), "critical ability" (evaluation of content suitable for one's own purpose), and "a capacity for representation" (by retextualizing into a new content of its own, useful for the knowledge needs of the user/reader) (New London Group, 1996). Considering the function of the image in new electronic documents, Unsworth (2001) provided a strong drive by analyzing a "recognition literacy" (i.e., decodification of its constituent signs), "reproduction literacy" (i.e., the proper organization of content for one's own use), and "reflective literacy" (i.e., the interpretation of the meaning and purpose of the content to enable its most effective application). Thus began the era of multiple literacies, starting in the 1990 s.

Multiple literacies were mainly aimed at developing competences for an "electronic discourse" along two dimensions:

a) the expert mastery of tools and instruments to capture and communicate content on the Internet, and

b) aptitudes for reading and writing of digital and hypermedia in order to assimilate information and generate knowledge.

Scientific literature echoed this terminological and conceptual fragmentation, following three routes, as suggested in Marzal (2009):

- A route in which the medium (communication channel) prevails over the message (content). This route includes literacies that are recognized under terms such as media literacy, technological literacy, computer literacy, computer literacy, and electronic literacy, among an extensive repertoire.

- A route that prioritizes the message over the medium, where the content is identified with the information, giving rise to notions such as "information skills," "information literacy," "web literacy," "Internet literacy," and other types emerging from fields where the informational message can be manipulated expertly.

- A route that gives preference to the level of expert handling of tools in professional environments, resulting in terms such as "computer skills," "technological abilities," "library skills," library literacy, and bibliographic instruction, as well as a wide range of others.

This evolution has a double effect for our purpose: the incorporation of information professionals, on the one hand, due to the value of such information; and on the other, the emergence of competences, with increasing educational value. In higher education, an educational model based on competences has been proposed through the Tuning Project, since 2000, while Unesco reports have provided an arena for the review of education from the point of view of competences (Jonnaert et al., 2006). Meanwhile, in 2007, the European Commission adopted its communication on "E-skills for the $21^{\text {st }}$ century," which was welcomed by the Competitiveness Council and started a development that led to the 2010 European Digital Agenda.

\subsection{A convergent process: informational and digital literacy}

While this divergence and fractionation seemed to result in a mosaic of literacies, the competences and educational dimension of effective information processing provoked a convergent movement, centered around two welcoming "specialties": informational and digital literacy.

The natural space of competences had been the world of work, but the development of the Internet and the impact of the web resulted in another dimension. An interesting debate thus began regarding an effective definition of the nature of competence, for application to the development of the knowledge society and digital economy, and how to apply it to ensure its sustainable development. Their definitional, behavioral, generic, or cognitive issues (Mulder; Weigel; Collins, 2007) as well as individual or social application models (Luengo-Navas; Luzón-Trujillo; Torres-Sánchez, 2008) were thus analyzed to arrive at some definitional elements that represent the most accepted meaning:

- They are associated with an attitude and behavior,

- They facilitate the successful completion of an activity,

- They allow activities to be carried out in an efficient and optimized fashion,

- They can be extrapolated to other fields of application.

Competences are associated with literacies due to the need to generate a new education, clearly related to competence, specifically for the knowledge society. A debate was formulated on the properties of competences in education (Carrera-Hernández; Marín, 2011), arriving at a convention on their functionality, including mobilization of knowledge, methods, and attitudes, in order to use learning content in decision-making and solve a scientific hypothesis or professional challenge. 
Competences for education had to be applied for efficient and intelligent treatment of content, resulting in a clear importance of the informative treatment and technological management of web content. Two types of competence thus resulted in two "specialties":

1) Digital literacy, requiring the development of a competence that allows understanding of the meaning of digital and virtual content, whose multifaceted and transversal nature requires the use of different textual, iconic, and auditory signs (Kwon; Hyun, 2014). This means digital reading, but followed by the production of one's own new content, i.e., digital writing. This concept of digital competence allowed the definition of digital literacy (Gilster, 1997) that was well founded on its object and objectives and which came to include terms such as cyberliteracy and hyperliteracy. Its impact became concrete due to its eminently technical nature.

2) Information literacy, whose undisputed object was information competence, as defined by the competence progress model defined by Bruce (2003). Information competences received great attention from professionals working in the documentation field, and soon also from researchers, such that it soon become a "specialty" with a strong impact, as evidenced by the vast scientific literature to which it has given rise. Due to its direct impact on the development of the information society, knowledge, and social inclusion, great effort has been invested in this specialty in terms of its definition (with successive and various "declarations"), codifiers (the norms ALA, ACRL, Anziil, etc.), application models and methods (Sconul, Big Six, and many others), specialized national and international conferences (ECIL among others), professional associations with specialized sections, journals specifically or preferentially publishing in this area (Journal of information literacy,

The objectives of data literacy soon became well defined based on an understanding of information represented by numbers in the broadest sense, together with the information used by algorithms and that can be presented visually

Communications in information literacy), websites such as registration and document repositories, incorporation into academic curricula via different modalities (formal, nonformal, and informal education), research and educational innovation projects, evaluation models, as well as its own indicators.

However, the strength of both of these specialties and their convergent power did not eliminate previous literacies; rather, they gave rise to new ones through their generalization. The reason seems to be that both form a vortex with a set of nearby literacies, resulting in a constellation model. Both, in their own domain, can be understood as the sun that gives meaning to the entire domain, while their application for specific environments or phenomena requires cooperation with one or more other literacies. Indeed, the illustrations that usually accompany texts referring to each of these "suns" visualize this cooperative model.

This "constellation" period was accompanied by the growing recognition of two clearly different competences: computer competence and information competence. On this occasion, however, the progress of the web towards a semantic and knowledge web, with the successive developments of Web 2.0, 3.0, and 4.0, revealed an obvious fact, viz. that both competences and their specialties could not continue in parallel, because their domains had fuzzy edges. The process, however, had to face the dilemma that digital competence assumed information competence. This debate started with the appearance of the term and concept of information literacy 2.0, as a space, field, and object to develop competence in collaborative environments while content was generated continuously, such as Web 2.0 (Carpan, 2010). This new specialty sparked a lively debate when Lombard (2016) introduced the concept of and term information fluency. Zhang (2002) introduced this concept based on interpretation of information fluency as the sum of computer literacy, information literacy, and critical thinking, an interpretation that led scholars and professionals to consider information fluency to be a superior and subsequent (and therefore substitute) arena for information literacy (Mani, 2004). In fact, critical information literacy was defined for the development of specific competences, as a means and way for critical evaluation using all the information and messages that are exchanged, consumed, or created in media and social networks, based on criteria and indicators related to education, sociology, and media psychology, thereby inculcating capacities for lifelong learning (Storksdieck, 2016). The impact on education, through active library participation, is evident in Tewell's (2015) analysis.

However, this debate and dilemma very soon highlighted a space for collaboration and convergence in digital information fluency by librarians, academics, technologists, and administrators, according to which technology supported this literacy, but in direct relation to the informational behavior of users (Sharkey, 2006). Its object, digital fluency (Briggs; Makice, 2012), was defined as a route for the development of competence from technological excellence to digital literacy (in a new semantic dimension), finally resulting in a social competence for knowledge.

On this occasion, the evolution of informational competition was more gradual, although a qualitative leap was made towards the competency domain of new web content. However, it was digital competences that would clearly begin to exhibit an orientation towards semantic

The aim of the target competences is to generate content according to the requirements and collaborative guidelines of the social web and in accordance with ethical behavior, while helping to build a digital identity and expertly "remix" content 
uses related to artificial intelligence. This thus affected their attitude and behavior characteristics (Noh, 2017), while escaping from their specific technical scenario to connect with informational competition (Gallardo-Echenique et al., 2015). In the Spanish library environment and in Rebiun's sphere of influence, the CRUE-TIC intersectoral mixed commission defined the concept of computer + information competences $(\mathrm{Cl} 2)$.

\subsection{A divergent process: multiliteracies}

From the end of the first decade of the 21st century, a pendulum swing (albeit unrecognized) occurred as an evolutionary line, once again divergent, began to be devised, ushering in the era of multiliteracies. Two phenomena strongly impacted on the two integrative literacies, starting a new process.

\subsubsection{Big data}

On the one hand, there is the phenomenon of so-called Big Data, viz. the immense volume of structured or unstructured data or combined datasets that constantly flood web environments and that, due to its own volume, speed of generation, and complexity, poses a serious challenge regarding its capture, treatment, management, and use, notwithstanding its both semantic and economic value. Two scenarios thus emerge: a technical one, aimed at structuring of data, where efforts to link data should be directed to devise methods to link and structure data and make it intelligible, according to the purpose; and another application, defining its use, which will give rise to open data, the purpose of which is to ensure that certain datasets are freely accessible and usable, via open source, open access, and free software, with all the ethical, authorship, and exploitation implications this implies.

In this second scenario, two conditions were soon identified: on the one hand, for its application in scientific environments, for which sharing of data and information is required, to place the spotlight on e-science, the Agenda for Developing e-Science in Research Libraries was published in 2007 by the Joint Task Force on Library Support for e-Science, in collaboration with the Association of College and Research Libraries (Berman, 2013), resulting in a discussion on scientific literacy; on the other hand, there was the need for data to be published in an intelligible way and for users to display competences to understand it, which should boost data literacy. In fact, it did not take long for the first proposals to teach data literacy courses emerged for inclusion in training modules (Stephenson; Caravello, 2007).

Visual literacy aims at the development of a visual metalanguage, with its iconic semiotics to support a visual semantics and thereby an appropriate "alphabet" for iconic reading, with its own grammar for visual discourse

The objectives of data literacy soon became well defined based on an understanding of information represented by numbers in the broadest sense, together with the information used by algorithms and that can be presented visually. The achievement of competences aimed at these goals had to pass through statistical literacy in data visualization, as well as the composition of a numerical narrative and argumentation, to bring the public closer to an intelligible use of Big Data, and empower them to manage their own data (Fontichiaro; Oehrli, 2016). The perennial terminological problem thus seemed to have been solved by imposing the term data literacy to the detriment of others, a specialty whose identity, considering the challenges faced, seemed to be based on specific competences (data searching and acquisition, data management, data conversion and interoperability, metadata, data curation, data preservation, data analysis and visualization, and ethics) (Koltay, 2015), as well as the development of a program to obtain these skills:

- Identify the context in which the data are created and reused

- Recognize the value, type, and formats in the data source

- Determine the need for the data

- Ensure appropriate access to the data according to the requirements

- Enable critical assessment of data sources

- Effective use of data for research

- Data analysis capacity

- Quantitative presentation of data

- Application of the results and a capacity for self-evaluation (Calzada; Marzal, 2013)

The academic foundation and robustness of data literacy originated from an interesting series of case studies on its pedagogical application, soon resulting in the appearance of three lines of development:

a) the use of data literacy to guarantee the development of transparency and governance of political and social entities (Koltay, 2016);

b) the need for educators to be trained in the competences of data literacy in order to train different groups according to their needs (Carlson; Bracke, 2015); and

c) its conversion into an invaluable instrument for the development and progress of scientific research, viz. true "e-research" (Carlson et al., 2011), with an interesting side application to enable data and content managers to map and visualize trends, clusters, and scientific collaborations in different fields and spaces (Stopar; Bartol, 2018).

Data literacy also fueled the growing interest in "imaging" data and its visualization. 


\subsubsection{Evolution of the web}

The evolution of the web, which requires an increasingly varied and specific set of competences, i.e., the "digital competences." In this maelstrom of digital skills, two phenomena impact on information and knowledge on the web: on the one hand, competences in the collaborative environments of social networks and interactive technologies; and on the other, the development of the image, not as an auxiliary, but as a means to present content and retrieve information and knowledge via visualization and virtualization. These info-communicational and visual competences thus acquire a seal of approval and demand their own literacies.

As pointed out above, it was not long before media literacy or digital media literacy appeared as the exercise of competences in the media domain and their corresponding languages, albeit later applying the principles of information literacy. This convergent path was promoted by Unesco in 2010 through the formulation of media and informational literacy (MIL), for which it published a set of indicators with which to measure its degree of achievement (Moeller et al., 2011), followed by a guide to train educators in these competences (Wilson et al., 2013). The aim of the target competences is to generate content according to the requirements and collaborative guidelines of the social web and in accordance with ethical behavior, while helping to build a digital identity and expertly "remix" content. The MIL combined technical knowledge in in-

A redefinition process was thus initiated in which the emerging concept of metaliteracy should be distinguished, recognizing the connection of users with platforms and instruments as the specific aim of transliteracy

fo-communicational competences in a sociocultural context, seeking to teach behaviors derived from a mentality and values relating to the use, consumption, and purpose of the media (Chen; Wu; Wang, 2011).

Info-communication competences also exhibited a greater progressive and specialized development as the media and web of social spaces progress, giving rise to social media literacy (Rheingold, 2010), together with the remarkable development of mobile devices and their educational effects through m-learning, thereby promoting mobile information literacy.

Meanwhile, visual competences have also made very encouraging progress. The need to carry out effective critical analysis of the image and its effects (esthetic, anatomical, cognitive psychological, anthropological cultural, mental imaginative, neurophysiological, psycholinguistic, semantic, or perceptual) had already been proposed as part of visual literacy in educational environments and by researchers from the 1950s until recently (Michelson, 2017). The progress observed in the visualization of information on the web, 3D devices, and virtual and augmented realities soon revealed the extraordinary impact of the image on content representation and knowledge acquisition. Educational bodies and libraries, which had long been active in visual literacy, acted promptly. The American Library Association (ALA/ACRL) published their Visual literacy competency standards for higher education in 2011, providing competency standards that were recognized as appropriate indicators to measure student achievements (Hattwig et al., 2013). The objective was to develop the skills necessary to understand and analyze contextual, cultural, ethical, esthetic, intellectual, and technical factors and elements in the use and production of audiovisual materials.

Visual literacy aims at the development of a visual metalanguage, with its iconic semiotics to support a visual semantics and thereby an appropriate "alphabet" for iconic reading, with its own grammar for visual discourse. In fact, experiences with visual literacy courses have resulted in the programming of activities that indicate a progressive competence path from esthetic literacy (methods of artistic analysis), illustrative literacy (methods of communication for a visual discourse complementary to the textual one), media literacy (the MIL method), iconic literacy (with learning of morphology, syntax, semantics, criticism, and emotional reading of images), and visual literacy, in accordance with the principles of the visual literacy standards. The taxonomy must include natural-lan-
guage terms that can serve as labels for
the represented classes, categories, or
subjects, but also order these according
to a structural model

\subsection{Intersectional nature}

The relevance of digital competences, the big data universe, and the beneficial effects of interdisciplinarity on all features of the web should herald a process not so much of convergence but of intersection between different literacy specialties.

A stimulus for this intersection process was provided by academic literacy, understood as an instrument by which actions for training competences can be developed into strategic plans for educational institutions. This is not a specialty, but rather an incorporation of multiliteracies into curricula. Its great chance came with the development of the "quality culture," in which universities had to justify their academic excellence based on indicators, which were then used to provide rankings. Academic literacy is implemented through training services of libraries or academic skills centers, with the aim of programming and offering courses via which students can acquire a sufficient methodological ability in the conversion of information into knowledge through the scientific method, and its dissemination through high-quality academic and professional work (MacMillan; MacKenzie, 2012). This literacy enables universities to recruit students in a competitive environment, and to demonstrate their excellence through the graduation of good scientists and professionals. 
Perhaps the most evident step forward in this transdisciplinarity project was the introduction of transliteracy, aimed at the development of competences for the domain of expert representation and assimilation of content from messages and media on social networks and digital media, exercising a capacity for multisequential and multimodal reading and writing but within its own narrative (Sukovic, 2014) through the combined use of oral, printed, and audiovisual web strategies, in an interaction environment that allows the use of different platforms and content management tools. This "cumulative" definition process has its origin and development in purely library environments, in addition to case study and practices, as considered by Hovious (2018) and placed in a more theoretical and competency context by Thomas et al. (2007). A redefinition process was thus initiated in which the emerging concept of metaliteracy should be distinguished, recognizing the connection of users with platforms and instruments as the specific aim of transliteracy (Dunaway, 2011). It was Ipri (2010) who set the theoretical foundation for this multiliteracy in the context of social practices and critical learning.

A further step towards its intersectional nature, being even more qualitative by focusing on web info-communication competences, was provided by two new multiliteracies, viz. new media literacy and metaliteracy. The conceptual foundation for new media literacy would be provided by Jenkins et al. (2009), as a specialty responsible for the development of connective and collaborative competences to guarantee the understanding of narratives based on different types of information in different formats and modalities, their evaluation, appropriation, concrete application, and interactions supported by collective negotiation and intelligence, and behaviors via digital identities. However, it was Lin et al. (2013) who described the evolution of this concept. They located their framework among the competences for media literacy, but also considered it to be a tool to address a new gap, for which they proposed an attractive evaluation system with indicators comprising consumption as well as prosumerization in digital and multimedia environments, especially social media, and the elements required for an educational effect (Durak; Saritepeci, 2019).

Through this process, metaliteracy emerged as a convergence of multiliteracies with the objective of developing competences to allow the student to evaluate their own competences based on critical thinking and "metacognition" via informational behavior within a collaborative environment (MacKey; Jacobson, 2014).

It was thus within this framework, at a stage with strong transdisciplinary dynamics, that efforts were made to identify a taxonomic model for multiliteracies in order to generate an "order" in which to frame different competence programs.

\section{An organization task: a model for an appropriate taxonomy}

As is well known, the concept of taxonomy introduced by Linnaeus refers to classification systems that are appropriate for biology and methodologically to the experimental sciences. However, at the end of the 19th century, the classifying power of taxonomies was extended to other areas of knowledge in both engineering and the social sciences, including documentation. In fact, in the documentation field, the ANSI/NISO Z39.19 standard defines taxonomy as

"An organized set of words or phrases used for organising information and primarily intended for browsing."

This functionality favoring navigation, exploration, search, and recovery in web environments has favored the typical hierarchical structure of taxonomies. In precise terms, the elements of a taxonomy are categories and subcategories that allow entities with common properties and characters to be related to one another to achieve clarity derived from logical-semantic coherence (Codina, 2019). If, in addition, the taxonomy is also required to "organize" a thematic area into classes of "subjects", a monohierarchical structure seems appropriate, with each class of subject occupying a unique position. To fulfill this requirement effectively, the taxonomy must include natural-language terms that can serve as labels for the represented classes, categories, or subjects, but also order these according to a structural model.

This need for "order" in the multiliteracy context was first raised around 2010, always being related to the concept of information literacy as its cornerstone. In 2011, Basili presented a report on the state of the art and good practices in information literacy, taking care to present its different conceptual dimensions. This effort was followed by Kutner and Armstrong in 2012 and Secker and Coonan in 2013, who addressed a "rethinking" of information literacy. Meanwhile, a new perspective was contributed in 2011 by MacKey and Jacobson, who proposed the re-creation of a conceptual framework for this literacy. They first proposed a redefinition as metaliteracy in 2013, and directly in 2014. Perhaps this provided the definitive motivation driving the effort to propose a taxonomic model, which indeed took over information literacy.

Multiliteracies, in effect, represent and seek to be applied to complex phenomena. For this reason, although monohierarchical taxonomic structures are useful, the truth is that classifications can (and must) address more than one organizational criterion, depending on the scope or application space, object, subject, purpose, and means of each multiliteracy. Thus, along with a hierarchical taxonomy proposal, a multifaceted taxonomy for the same entity seemed both viable and convenient. 
A strong taxonomic proposal was made by Stordy (2015), who offered a significantly faceted model based on the frameworks proposed by Lankshear and Knobel (2007) and Street (1995). That model encouraged the detection of proposals for the classification and organization of multiliteracies, and this was undertaken by the $\mathrm{R}+\mathrm{D}+\mathrm{i}$ research project Voremetur, one of whose phases aims to design competency programs within the framework of the emerging discipline of metaliteracy, along with instruments, materials, and evaluation systems to obtain knowledge from iconic and digital information. Two other models seem to derive from Stordy's model, ultimately leading to three models, one hierarchical and two faceted:

\section{Stordy's faceted model}

This taxonomic model is based on the classification of "literacies" based on the traditional concept of "literacy," viz. the ability to read and write by decoding signs. The model is structured along two axes:

- Categories, which depend on the medium, environment, and space

- Models, which depend on the informational attitude and behavior

Each axis integrates two subaxes, inspired by the proposal of Lankshear and Knobel: autonomous and ideological for the models, and conventional and new for the categories, resulting in a table on which each literacy must be fixed (Table 1):

Table 1. Taxonomic model explained by Stordy

\begin{tabular}{|c|c|c|c|c|}
\hline \multicolumn{5}{|c|}{ Classification categories } \\
\hline \multirow{4}{*}{$\begin{array}{l}\text { Classification } \\
\text { models }\end{array}$} & & Conventional literacies & New literacies & \\
\hline & \multirow[b]{2}{*}{$\begin{array}{l}\text { Autonomous } \\
\text { (cognitive } \\
\text { ability) }\end{array}$} & \multirow{2}{*}{$\begin{array}{l}\text { Conventional literacies with an } \\
\text { autonomous perspective. } \\
\text { Not necessarily including } \\
\text { technological skills: library, bi- } \\
\text { bliographic, literacy instruction, } \\
\text { and its norms }\end{array}$} & Peripheral concept (technology only) & $\begin{array}{l}\text { Paradigmatic concept (techni- } \\
\text { que and behavior) }\end{array}$ \\
\hline & & & $\begin{array}{l}\text { Peripheral concept of autonomous } \\
\text { perspective } \\
\text { digital literacy, media literacy, MIL, com- } \\
\text { puter literacy, social media literacy, etc. }\end{array}$ & $\begin{array}{l}\text { Autonomous perspective of } \\
\text { paradigmatic concept } \\
\text { literacy } 2.0, \text { metaliteracy, new } \\
\text { media literacy, visual literacy, etc. }\end{array}$ \\
\hline & $\begin{array}{l}\text { Ideological } \\
\text { (social practice) }\end{array}$ & $\begin{array}{l}\text { Conventional literacies with } \\
\text { perspective of } \\
\text { ideological } \\
\text { scientific literacy, academic } \\
\text { literacy, multiliteracy research }\end{array}$ & $\begin{array}{l}\text { Peripheral concept of ideological } \\
\text { perspective } \\
\text { Internet literacy and/or web literacy }\end{array}$ & $\begin{array}{l}\text { Paradigmatic concept of ideo- } \\
\text { logical perspective } \\
\text { transliteracy }\end{array}$ \\
\hline
\end{tabular}

\section{Jacobson \& MacKey and Secker \& Coonan evolutionary model}

This model can be derived from an analysis of the conceptual frameworks proposed by both pairs of authors. It is a taxonomic model, also faceted and evolutionary, expressed in three phases and whose objective is to typify literacies:

- The first stage, where "multiliteracies" arise, is based on their adaptation to a specific environment and instruments, enabling their classification into discrete or unique literacies, when the space, object, and application is their own and applied in a pure way, or into combined or "composite" literacies, when there is a combination of techniques, instruments, and methods, to achieve an optimal application in a given space or object;

- Multimodal literacies, whose objective is to convert the student into a domain expert in different literacies, establishing a cooperative link between them, that is, a symbiotic model of literacies;

- Transliteracy, which seeks to train domain experts in information competences that can be used in different fields, environments, media, etc., cooperating with the specific competence in each to achieve an optimization of knowledge that is both intersectional and adaptable.

This model can be represented according to Table 2:

Table 2. Taxonomic model derived from Secker \& Coonan and Jacobson \& Mackey

\begin{tabular}{|c|c|c|}
\hline \multicolumn{2}{|c|}{ Multiliteracies } & Combined or "composite" literacies \\
\hline "Discrete" or unique literacies & New media literacy \\
ICT literacy \\
Digital literacy \\
Cyberliteracy \\
Visual literacy \\
Mobile literacy \\
Information fluency \\
Metaliteracy \\
Critical information literacy
\end{tabular}




\section{The competency model of Bawden}

This is a hierarchical-type model whose taxonomic basis lies in the interpretation of competences according to various types according to the evolution of the reading-writing context, thereby demanding its own training specialty or literacy. This model is linear and reproduces the evolution described above. It can be represented in Table 3:

Table 3. Taxonomic model derived from Bawden

\begin{tabular}{|l|l|}
\hline \multicolumn{1}{|c|}{ Type of competence } & \multicolumn{1}{c|}{ Competency specialty } \\
\hline Information competence about the message & $\begin{array}{l}\text { Bibliographic instruction, library instruction, geographic literacy, agrarian literacy, business } \\
\text { literacy, legal literacy, etc. (as many literacies as knowledge or professional areas) }\end{array}$ \\
\hline Information competence on the medium & $\begin{array}{l}\text { ICT literacy, electronic literacy, Internet literacy, media literacy, multimedia literacy, network } \\
\text { literacy, hyperliteracy, etc. }\end{array}$ \\
\hline $\begin{array}{l}\text { Information competence regarding knowled- } \\
\text { ge, wisdom, and education on the web }\end{array}$ & $\begin{array}{l}\text { Information literacies } \\
\text { Constellation concept, resulting in information competence related to knowledge (assimila- } \\
\text { ting) and wisdom (application), which can be applied to all media and messages, in coopera- } \\
\text { tion with the specific competence of each }\end{array}$ \\
\hline $\begin{array}{l}\text { Computer-information competences (CI2) and } \\
\text { digital and information fluency }\end{array}$ & $\begin{array}{l}\text { Digital literacy, media and information literacy, data literacy, mobile literacy, cyberliteracy, } \\
\text { health literacy }\end{array}$ \\
\hline Digital competences & Academic literacy, science literacy, critical information literacy \\
\hline Digital and info-communication competences & Visual literacy, new media literacy, metaliteracy \\
\hline
\end{tabular}

There are, therefore, initiatives to test a taxonomic model that need not be unique and universal. The reason for this is simple: an ordered conceptual framework for basic research will be much easier, but above all much more effective, to apply for the design and development of competency programs in education, as typically applied in research by academics and professionals. The progress from one investigation to another necessarily passes through the design of a "metamodel, " understood as a set of concepts, norms, and relationships used to define a "family" of related methodologies (Henderson-Sellers; González-Pérez, 2005) and whose purpose is to provide an appropriate framework for interpretive analysis of literacy development and action planning, plans, and programs for different contexts and fields of application.

\section{The development of a taxonomic model: Voremetur}

The taxonomic models presented herein can be used in investigation processes, as we show below in a case study of the Voremetur research project. This acronym refers to a coordinated R+D+i project, within the State Research, Development, and Innovation Program aimed at Challenges of Society, Vocabularies for a network of archives and collections of media art and its effects: Metaliteracy and tourism of knowledge, with reference HAR2016-75949-C2-1-R, granted by the Ministry of Economy and Competitiveness and started in December 2016.

\subsection{The context for the development of a taxonomic model and its metamodel}

The scientific subject of this project is the tendency towards virtualization of works of art and historical documents, among which the collections of Media Art represent a very instructive challenge as they are made up of works created using technological tools on which to test new preservation formats, as the tools are themselves obsolete. The process requires techniques for creating, storing, and preserving files, records, and electronic documents from this type of collection, with the aim of preserving such material in the context of digital continuity.

Due to its coordinated nature, the project is made up of two subprojects:

1) AEMA, whose purpose is the constitution of a network of archives and collections of Media Art in Spain (to provide a basis for its implementation, to be followed by Latin America), as well as the application of this network to support the development of actions for a knowledge tourism plan;

2) Temuweb, which aims to develop digitization protocols using a standardized set of guidelines (an embryonic standard) to ensure the preservation, accessibility, display, and interoperability of these collections in structured repositories within the network.

The general aim of Temuweb, in addition to a standardized digitization protocol, is to develop processes to describe the digital objects in Media Art in a web catalog, including metadata for efficient semantic labeling of its contents. This process must be supported by the generation of a specific thesaurus for Media Art, whose descriptors, together with terminological sources for this domain, will emerge from the metadata and the labels of the collections, which will be edited using appropriate software that can manage these descriptors and images while taking advantage of interoperable functionality from a linked open data system. Finally, Temuweb should test the application scope and introduce this into the approach and instructional design of competency programs within the framework of metaliteracy, with its instruments, materials, and evaluation system, so that the collections of Media Art and its objects can act as educational digital objects (ODEs) for the effective development of info-communicational, visual, and iconic competences. This aim defines a phase and one of the results of Voremetur, thus requiring a taxonomic model and metamodel to develop an appropriate competence program. 
This choice of designing a teaching innovation competence program within the parameters of metaliteracy seems natural due to the characteristics of the Media Art collections: the taxonomic models, especially the third, competence model (but also the possible implementations of the other two), yield a close collaboration with visual literacy and new media literacy for expert iconic and visual literacy, while its own principles of self-evaluation and, especially, of expert mastery of communication in networks allow the conversion of the works in Media Art into particularly effective ODEs.

\subsection{The taxonomic method for a feasible metamodel}

Logically, there should be but one metamodel, although it will derive from the three taxonomic models described above. The design of the metamodel followed the prototypical phases for the elaboration of a taxonomy as perfectly reviewed by Codina (2019). We thus now present the phases used to elaborate the taxonomy, with its phases, to sketch the metaliteracy metamodel of Voremetur, emphasizing that the aim is not to present the details of the search, collection, organization, and scientometric analysis but rather some results that validate the conceptual categories included in the metamodel.

1) Definition of the field and object (entity) where the taxonomy will exercise its function of classificatory order. In the case of Voremetur, this is the application of metaliteracy as a necessary conceptual framework for the instructional design of conceptual programs in higher education, with the aim of info-communication competences and visual and iconic reading.

2) Identification of keywords, recognized as terms, to serve as sufficient semantic labels for the categories of the taxonomy. The search for these keywords was carried out among the words constituting the titles and summaries reported in the databases and that, when exceeding or dropping below a threshold of statistical frequency, have power to represent the content. These keywords must be compared with the language of the specialty, in this case as directly referring to metaliteracy, thereby acquiring superior semantic power as terms. As terminology sources, a selection of databases and repositories consisting of ERIC, LISA, Ebsco, ABI Inform, Safari, Springer, Academic SP, Science Direct, Web of Science, Scopus, and Capes was chosen. The central search term was metaliteracy, implemented via searches on information literacy, visual literacy, and new media literacy (in English, naturally), using the secondary period from 2005 to 2011, when the mention of metaliteracy stopped being episodic but was still not widespread, and, primarily, from 2011 to 2019, because this coincides with the time when metaliteracy had already been defined with its own space and principles.

3) A semantic control to convert keywords into terms. The research team was divided to analyze the results from each database and repository where metaliteracy, or metaliteracy with any of the other search concepts, appeared. Having selected the representative keywords in each search niche, they were compared to identify synonyms or polysemy, then refined based on their representativeness according to the "objectives" of metaliteracy. They were then converged and normalized to form a list of terms that was the basis for designing the categories of the taxonomy.

4) Definition of the structure of the taxonomy by categories. For this definition, it is very important to establish the criteria for organizing the categories. According to the techniques highlighted by Codina (2019), the bottom-up approach was applied. Thus, the semantic spaces were determined from the terms, then each was labeled with terms having greater representation capacity and therefore greater capacity to accept encompassed terms, thereby allowing a "super-ordering" from lower to higher categories. Finally, the viability of the established categories was confirmed by relating the scientific literature obtained from searches in the databases and repositories to each one of them, thereby verifying their organizing and classifying power.

\subsection{Taxonomic categories for a metamodel proposal}

The scheme of the taxonomic categories is presented in Table 4.

Table 4. Taxonomic categories for metaliteracy in the Voremetur universe

1. Metaliteracy as an area of knowledge and professional specialty

1.1. State of the art

1.2. Conceptual framework: notions, concepts, definitions, classifications, cooperation with multiliteracies

1.3. Conceptual evolution: history of its definition, currents, "schools," and trends

1.4. Theories

1.5. Objective:

1.5.1. Competences with their types, styles, and evolution

1.5.2. Reading-writing on the web and metaliteracy

1.6. Objectives: competence programs in any field

1.7. Specialty language: glossaries, vocabularies, specific language

1.8. Metaliteracy and informational behavior

1.9. Metaliteracy and behavior in social media

1.10. Metaliteracy: auxiliary specialty and sciences for metaliteracy

2. Elements and instruments of metaliteracy

2.1. Constituent elements of metaliteracy

2.2. Interpretation and application tools

2.3. Analysis and interpretation models and metamodels

2.4. Metaliteracy techniques and their tools and instruments 


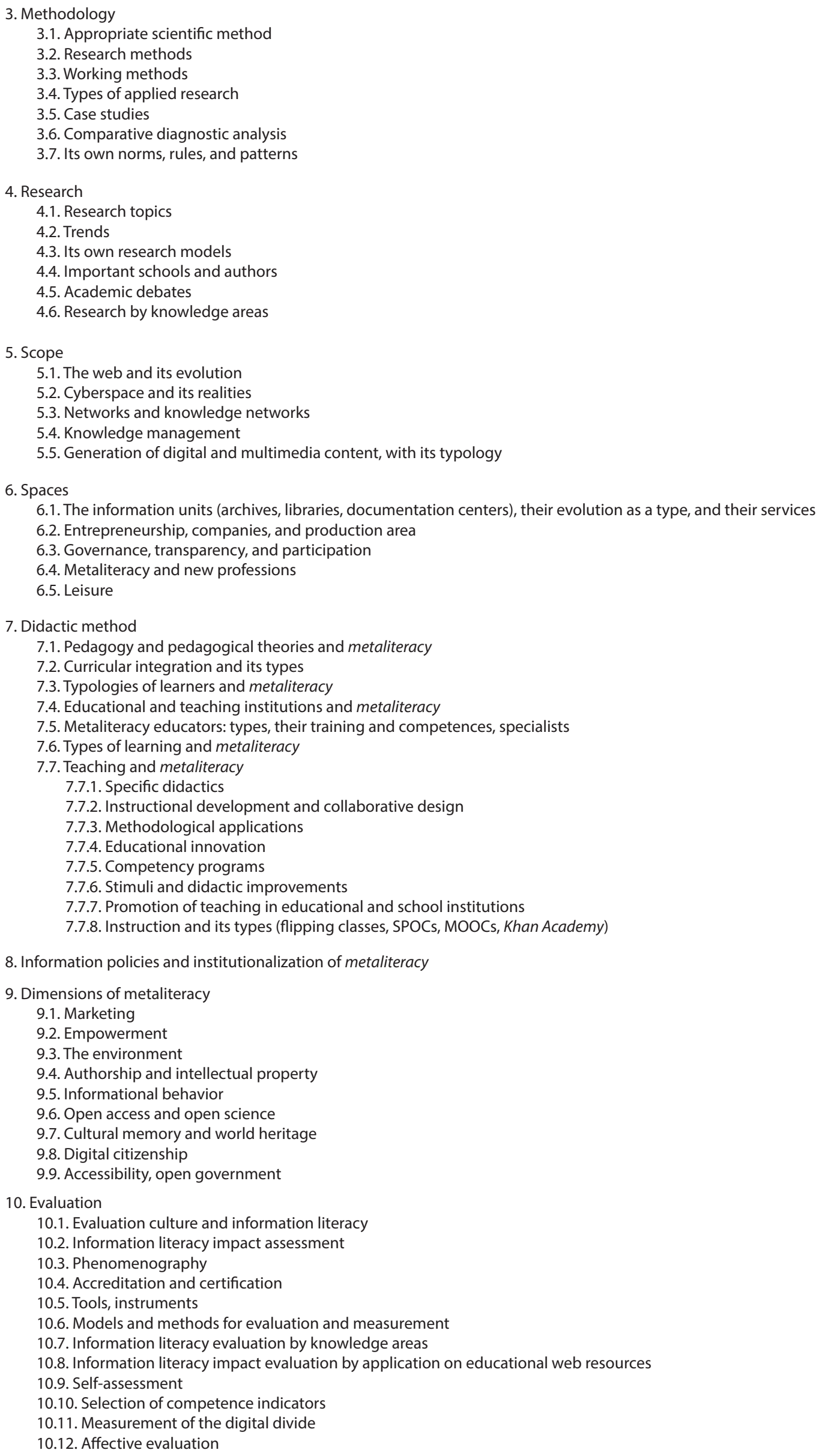

8. Information policies and institutionalization of metaliteracy

9. Dimensions of metaliteracy
9.1. Marketing
9.2. Empowerment
9.3. The environment
9.4. Authorship and intellectual property
9.5. Informational behavior
9.6. Open access and open science
9.7. Cultural memory and world heritage
9.8. Digital citizenship
9.9. Accessibility, open government

10. Evaluation

10.1. Evaluation culture and information literacy

10.2. Information literacy impact assessment

10.3. Phenomenography

10.4. Accreditation and certification

10.5. Tools, instruments

10.6. Models and methods for evaluation and measurement

10.7. Information literacy evaluation by knowledge areas

10.8. Information literacy impact evaluation by application on educational web resources

10.9. Self-assessment

10.10. Selection of competence indicators

10.11. Measurement of the digital divide

10.12. Affective evaluation 
Once the taxonomic scheme has been determined, it seems useful to demonstrate its potential benefits in the formulation of a metamodel, as a basis for programming:

a) Paradigmatic framework.

Metaliteracy will be considered as a "new conceptually paradigmatic autonomous literacy." This implies that metaliteracy is realized in the development of cognitive competences oriented towards the development of the person and specifically their technical skills, but also behavior. This last statement allows metaliteracy to cooperate with academic literacy, an ideological literacy, by influencing the social and conventional dimension.

b) Conceptual framework.

Metaliteracy is understood as an "academic specialty", part of multiliteracy, whose conceptual foundation is to be a combined or "compound" literacy, which implies that it is a "confederate" multiliteracy: its design and application will be carried out in cooperation and symbiosis with other multiliteracies. For reasons associated with the project, in Voremetur this symbiotic cooperation will be with information literacy, "new media literacy", and "visual literacy". Having recognized its "composite" character and determined its confederate multiliteracies, metaliteracy must develop (i.e., seek an application route from basic to applied research) to become a multimodal literacy by manifesting itself through academic literacy.

c) Object of study and field of research.

According to the paradigmatic and conceptual frameworks described, these are undoubtedly the "digital competences," as defined by the European Union as

"the one that implies critical and safe use of technologies by information society for work, free time, and communication. These are founded on basic ICT skills, viz. the use of computers to retrieve, evaluate, store, produce, present, and exchange information, and to communicate and participate in collaborative networks through the Internet,"

or more specifically info-communications (via coordination with "new media literacy") and visuals (via coordination with "visual literacy").

d) Factors for programming.

- Higher education as a field of application. The competency program will be presented as a factor of "academic excellence", through "educational innovation", in accordance with the 21st century models of education promoted by Unesco programs, as well as the European Union. It will be presented as an element of development of new educational modalities, lifelong learning, and employability via entrepreneurship.

- Academic literacy, as a principle that allows the incorporation of competency programs as an element of the strategic plans of universities. The proposal of these competency programs will be considered in universities as part of transversal and nonformal education, which acquires its own personality through academic literacy as a service for a set of programs and activities offered to students to develop their competences and abilities to optimize their learning and empower them towards high-quality employment. Through this literacy, metaliteracy programs must develop their own evaluation model, which will transform them into an indicator of excellence for international quality rankings of universities. This should be considered as a service through university libraries, via academic skills centers.

- Educommunication, as an appropriate area of knowledge to design competency programs as a proposal for transversal or optional subjects by university departments. Educommunication can offer an ideal framework for instructional and methodological design, as well as allow adequate introduction into the design of university curricula. This dimension offers notable benefits, thus the research team carried out the searches based on the aforementioned databases and repositories, using the same chronological limits, searching for metaliteracy and educommunication. The results were very scarce, but far from being an obstacle, this shows, on the contrary, that this is an emerging line of research and propitious to explore.

- Suitable and specific teaching material for these competency programs. As pointed out above, these materials should be the ODEs, adjusted to a theoretical, methodological, and evaluative framework typical of a metaliteracy applied through the artistic and museum objects of Media Art and contemporary artistic practices. There are various definitions of ODEs, but for our purposes, the four levels of aggregation recognized by the LOM-ES (learning object metadata-Spanish) standard should serve:

i) level 1, i.e., the different constituent media objects;

ii) level 2, i.e., the learning objects that structure the content of the objects (with their introductory, expository, illustrative, and evaluative modules);

iii) level 3, expressing the didactic sequence (programming);

iv) level 4, viz. the articulation of a complete didactic program.

- An evaluation system, which, due to its specific characteristics and adaptable to the objective of a competence metaliteracy program for Media Art, follows the set of indicators proposed by Marzal and Borges (2017). 


\section{Conclusions}

The need to find order (taxonomic, as we argue here) in the universe of literacies and multiliteracies leads us to consider that the incorporation of teaching innovation programs in higher education for the development of digital competences is a necessity for universities in the $21^{\text {st }}$ century as they embark on the quest for academic excellence. This finding represents an important challenge due to the need for an unequivocal definition of competences, informational competences, info-communicational competences, and finally digital competences. The reliable definition of these competences, as objects of research, supports their respective academic specialties, posing then the problem of how to order this universe, since it is necessary to elucidate the type of connection, subordination, relationship, and cooperation between these competences in order to generate an organic scheme of specialties, which is all the more necessary as such a framework is necessary for the application of educational innovation programs, supported by academic literacy.

The motivation of the agents that are most directly involved in the development of the knowledge society and its media shows that digital competences play a relevant role as a determining factor in generating knowledge in universities of excellence, but also due to the impact of social cohesion and sustainable development on the corporate social responsibility of higher education institutions. For this reason, the actions of competent institutions of the European Union, international organizations, analysis bodies, and economic and social prospecting must be known. The objective and desired result is to construct a well-defined conceptual framework for the incorporation of competency programs, whose epicenter is information literacy (due to its greater scope and application potential), with implementations from metaliteracy, "visual literacy", and "new media literacy", proposed within the strategic planning that academic literacy can provide.

This context leads to a diachronic line describing the challenges and responses that the different literacies in technological environments and on the web have posed to competences. The result is a "conceptual map" over time, concatenating different literacies and multiliteracies, which have not been revolutionary, but rather have included, associated, and reinterpreted previous ones. Having drawn this map, we were able to attempt to deduce a scheme, as a basis for a taxonomic proposal.

Having sketched the taxonomic proposal in this way, its possible benefits were found to include the incorporation of competence programs into the academic curriculum through well-planned instructional and programmatic designs and clarifying which literacies are required in higher education, and according to which competency objectives. For this reason, the definition of a multiliteracy taxonomy calls for application metamodels and cooperation between multiliteracies, targeting taxonomic categories of development in specific programs. Undoubtedly, the scientific community has acknowledged this need by outlining taxonomic models, although only one has been explicitly proposed. The scheme represented in Table 4 can be considered to represent a proposal for useful taxonomic categories for the design of info-communicational and visual competency development programs, considering the initiatives and experience that the research team develops through the teaching innovation programs applied in different university degrees.

In this regard, the work to edit suitable ODEs in these programs and the alignment of the program with educommunication seem extremely important lines of work. The study naturally aims to suggest attractive lines of research for specialists: the need to reflect on how a taxonomic framework ensures not only its effectiveness, but also its interoperability and compatibility, for the sake of coordination between international academic teams and cross-disciplinary domains; the incorporation of the perspective of communication skills not only regarding their media, but also as a basis for collaboration in networks, learning, and web publishing; the consideration of ODEs as ideal teaching materials for competency programs, requiring serious reflection on their design and effectiveness for teaching competences, in order to better adapt to an environment of data visualization and content virtualization.

\section{References}

Association of College and Research Libraries (2011). ACRL Visual literacy competency standards for higher education. American Library Association. http://www.ala.org/acrl/standards/visualliteracy

Basili, Carla (2011). Report on current state and best practices in information literacy. European Commission: Empatic. http://empatic.ceris.cnr.it/ita/Rapporti/Report-on-Current-State-and-Best-Practices-in-Information-Literacy

Bawden, David (2002). "Revisión de los conceptos de alfabetización informacional y alfabetización digital". Anales de documentación, v. 5, pp. 361-408.

http://revistas.um.es/analesdoc/article/view/2261

Berman, Elizabeth (2013). "Transforming information literacy in the sciences through the lens of e-science". Communications in information literacy, v. 7, n. 2, pp. 161-170.

https://doi.org/10.15760/comminfolit.2013.7.2.148

Briggs, Christian; Makice, Kevin (2012). Digital fluency: Building success in the digital age. Digital fluency. ISBN: 9780 615642949 
Bruce, Christine-Susan (2003). "Las siete caras de la alfabetización en información en la enseñanza superior". Anales de documentación, v. 6, pp. 289-294.

https://revistas.um.es/analesdoc/article/view/3761

Calzada, Javier; Marzal, Miguel-Ángel (2013). “Incorporating data literacy into information literacy programas: Core competencies and contents". Libri, v. 63, n. 2, pp. 123-134.

https://doi.org/10.1515/libri-2013-0010

Carlson, Jake R.; Fosmire, Michael; Miller, Chris; Nelson, Megan R. Sapp (2011). “Determining data information literacy needs: A study of students and research faculty". Libraries Faculty and Staff Scholarship and Research, v. 11, n. 2, pp. 629-657.

https://docs.lib.purdue.edu/lib_fsdocs/23

Carlson, Jake; Bracke, Marianne Stowell (2015). "Planting the seeds for data literacy: Lessons learned from a student-centered education program". International journal of digital curation, v. 10, n. 1, pp. 95-110.

https://doi.org/10.2218/ijdc.v10i1.348

Carpan, Carolyn (2010) “Introducing information literacy 2.0”. College \& undergraduate libraries, v. 17, n. 1, pp. 106-113. https://doi.org/10.1080/10691310903584627

Carrera-Hernández, Celia; Marín, Rigoberto (2011). "Modelo pedagógico para el desarrollo de competencias en educación superior". Actualidades investigativas en educación, v. 11, n. 1, pp. 1-32

Chen, Der-Thanq; Wu, Jing; Wang, Yu-Mei (2011). "Unpacking new media literacy”. Journal of systemics and informatics, v. 9, n. 2, pp. 84-88.

http://www.iiisci.org/journal/sci/Ful/Text.asp?var=\&id=OL508KR

Codina, Lluís (2019). Qué son las taxonomías y cómo se aplican a sitios web. https://www.lluiscodina.com/taxonomia-sitio-web

Dunaway, Michelle-Kathleen (2011). "Connectivism: learning theory and pedagogical practice for networked information landscapes". Reference services review, v. 21, n. 1, pp. 30-51.

https://doi.org/10.1108/00907321111186686

Durak, Hatice-Yildiz; Saritepeci, Mustafa (2019). "Modeling the effect of new media literacy levels and social media usage status on problematic internet usage behaviours among high school students". Education and information technologies, v. 24, n. 4, pp. 2205-2223.

https://doi.org/10.1007/s10639-019-09864-9

Fontichiaro, Kristin; Oehrli, Jo-Angela (2016). "Why data literacy matters". Knowledge quest, v. 44, n. 5, pp. 21-27.

Gallardo-Echenique, Eliana E.; Minelli-De-Oliveira, Janina; Marqués-Molías, Luis; Esteve-Mon, Francesc (2015). “Digital competence in the knowledge society.0". Merlot. Journal of online learning and teaching, v. 11, n. 1, pp. 1-16. https://jolt.merlot.org/vol11no1/Gallardo-Echenique_0315.pdf

Gilster, Paul (1997). Digital literacy. Hoboken, NJ: John Wiley \& Sons. ISBN: 0471165204

Hattwig, Denise; Bussert, Kaila; Medaille, Ann; Burgess, Joanna (2013). “Visual literacy standards in higher education: new opportunities for libraries and student learning". Portal: Libraries and the academy, v. 13, n. 1, pp. 61-89.

https://digital.lib.washington.edu/researchworks/bitstream/handle/1773/25328/Hattwig_etal_VisualLiteracy_ portal2013.pdf

Henderson-Sellers, Brian; González-Pérez, César (2005). "A comparison of four process metamodels and the creation of a new generic standard". Information and software technology, v. 47, n. 1, pp. 49-65.

https://doi.org/10.1016/j.infsof.2004.06.001

Hovious, Amanda (2018). "Towards a socio-contextual understanding of transliteracy". Reference services review, v. 46, n. 2, pp. 178-188.

https://doi.org/10.1108/RSR-02-2018-0016

Ipri, Tom (2010). "Introducing transliteracy: What does it mean to academic libraries?". College \& research library news, v. 71, n. 10.

https://crln.acrl.org/index.php/crlnews/article/view/8455/8698

Jacobson, Trudi E.; Mackey, Thomas P. (2013). "Proposing a metaliteracy model to redefine information literacy". Communications in information literacy, v. 7, n. 2, pp. 84-91.

https://doi.org/10.15760/comminfolit.2013.7.2.138 
Jenkins, Henry; Purushotma, Ravi; Wiege, Margaret; Clinton, Katie; Robinson, Alice J. (2009). Confronting the challenges of participatory culture. Media education for the $21^{\text {st }}$ century. Cambridge, Mass: MIT Press. John D. and Catherine T. MacArthur Foundation Reports on Digital Media and Learning. ISBN: 9780262513623

Jonnaert, Philippe; Barrette, Johanne; Masciotra, Domenico; Yaya, Mane (2006). Revisión de la competencia como organizadora de los programas de formación: hacia un desempeño competente. Ginebra: Oficina Internacional de Educación, BIE / Unesco.

http://www.ibe.unesco.org/fileadmin/user_upload/COPs/Pages_documents/Competencies/ORE_Spanish.pdf

Kutner, Laurie; Armstrong, Alison (2012). "Rethinking information literacy in globalized world". Communications in information literacy, v. 6, n. 1, pp. 24-33.

https://doi.org/10.15760/comminfolit.2012.6.1.115

Koltay, Tibor (2015). "Data literacy: in search of a name and identity". Journal of documentation, v. 71, n. 2, pp. $401-415$. https://doi.org/10.1108/D-02-2014-0026

Koltay, Tibor (2016). "Data governance, data literacy and the management of data quality". IFLA journal, v. 42, n. 4, pp. 303-312.

https://doi.org/10.1177/0340035216672238

Kwon, S.; Hyun, S. (2014). "A study of the factors influencing the digital literacy capabilities of middle-aged people in online learning". Korean journal of the learning sciences, v. 8, n. 1, pp. 120-140.

Lankshear, Colin; Knober, Michele; Bigun, Chris; Petres, Michael (eds.). (2007). Sampling "the new" in new literacies. New York: Peter Lang. ISBN: 9780820495231

Lin, Tzu-Bin; Li, Jen-Yi; Deng, Feng; Lee, Ling (2013). “Understanding new media literacy: An explorative theoretical framework". Journal of educational technology \& society, v. 16, n. 4, pp. 160-170.

https://drive.google.com/open?id=1JbHF7dGdN3jWKOBMZe_GaOMOm85aOwGR

Lombard, Emmet (2016). "Information fluency: Not information literacy 2.0". The journal of academic librarianship, v. 42, pp. 281-283.

https://doi.org/10.1016/j.acalib.2016.04.006

Luengo-Navas, Julián-Jesús; Luzón-Trujillo, Antonio; Torres-Sánchez, Mónica (2008). “Las reformas educativas basadas en el enfoque por competencias: una visión comparada". Profesorado. Revista de currículum y formación del profesorado, v. 12, n. 3, pp. 1-10.

https://recyt.fecyt.es/index.php/profesorado/article/view/42464/24380

Mackey, Thomas P.; Jacobson, Trudi E. (2011). "Reframing information literacy as a metaliteracy". College \& research libraries, v. 72, n. 1, pp. 62-78.

https://crl.acrl.org/index.php/crl/article/download/16132/17578

Mackey, Thomas P.; Jacobson, Trudi E. (2014). Metaliteracy: Reinventing information literacy to empower learners. London: Facet. ISBN: 9781555709891

MacMillan, Margy; MacKenzie, Allison M. (2012). "Strategies for integrating information literacy and academic literacy. Helping undergraduate students make the most of scholarly articles". Library management, v. 33, n. 8-9, pp. 525-535. https://pdfs.semanticscholar.org/0f45/13e6e03454b4974140cfcb801c9ea565e3b8.pdf https://docs.lib.purdue.edu/iatul/2012/papers/16

Mani, Nandita (2004). "On my mind. From information literacy to information fluency". American libraries, v. 35, n. 2, p. 30.

https://www.jstor.org/stable/25649062

Marzal, Miguel-Ángel (2009). “Evolución conceptual de la alfabetización en información a partir de la alfabetización múltiple en su perspectiva educativa y bibliotecaria". Investigación bibliotecológica, v. 23, n. 47, pp. 129-160. https://doi.org/10.22201/iibi.0187358xp.2009.47.16959

Marzal, Miguel-Ángel; Borges, Jussara (2017). “Modelos evaluativos de metaliteracy y alfabetización en información como factores de excelencia académica”. Revista española de documentación científica, v. 40, n. 3, pp. 222-231, e184. https://doi.org/10.3989/redc.2017.3.1410

Michelson, Alan (2017). "A short history of visual literacy: the first five decades". Art libraries journal, v. 42, n. 2, pp. 95-98.

https://doi.org/10.1017/alj.2017.10

Moeller, Susan; Joseph, Ammu; Lau, Jesús; Carbo, Toni (2011). Towards media and information literacy indicators. Paris: Unesco.

https://www.ifla.org/files/assets/information-literacy/publications/towards-media-and-Information-literacy-indicators.pdf 
Mulder, Martin; Weigel, Tanja; Collins, Kate (2007). "The concept of competence in the development of vocational education and training in selected EU member states: a critical analysis". Journal of vocational education and training, v. 59 , n. 1 , pp. $67-88$.

https://doi.org/10.1080/13636820601145630

New London Group (1996). "A pedagogy of multiliteracies: designing social futures". Harvard educational review, v. 66, n. 1, pp. 1-29.

https://www.sfu.ca/ decaste/newlondon.htm

Noh, Younghee (2017). "A study on the effect of digital literacy on information use behavior", Journal of librarianship and information science, v. 49, n. 1, pp. 26-56.

https://doi.org/10.1177/0961000615624757

Pinto, María; Cordón, José-Antonio; Gómez-Díaz, Raquel (2010). “Thirty years of information literacy (1977-2007): A terminological, conceptual and statistical analysis". Journal of librarianship and information science, v. 42, n. 1, pp. 3-19. https://doi.org/10.1177/0961000609345091

Rheingold, Howard (2010). "Attention and other $21^{\text {st }}$-century social media literacies". Educause review, v. 45, n. 5, pp. 14-24.

https://er.educause.edu/articles/2010/10/attention-and-other-21stcentury-social-media-literacies

Secker, Jane; Coonan, Emma (eds.) (2013). Rethinking information literacy: A practical framework for supporting learning. London: Facet Publishing. ISBN: 9781856048224

Sharkey, Jennifer (2006). "Towards information fluency: Applying a different model to an information literacy credit course". Reference services review, v. 34, n. 1, pp. 71-85.

https://doi.org/10.1108/00907320610648770

Snavely, Loanne; Cooper, Natasha (1997). "The information literacy debate". Journal of academic librarianship, v. 23, n. 1, pp. 9-14.

https://doi.org/10.1016/S0099-1333(97)90066-5

Stephenson, Elizabeth; Caravello, Patti-Schiffer (2007). "Incorporating data literacy into undergraduate information literacy programs in the social sciences". Reference services review, v. 35, n. 4, pp. 525-540.

https://doi.org/10.1108/00907320710838354

Stopar, Karmen; Bartol, Tomaz (2019). “Digital competences, computer skills and information literacy in secondary education: mapping and visualization of trends and concepts". Scientometrics, v. 118, n. 2, pp. 479-498.

https://doi.org/10.1007/s11192-018-2990-5

Stordy, Peter (2015) "Taxonomy of literacies". Journal of documentation, v. 71, n. 3, pp. 456-476.

https://doi.org/10.1108/JD-10-2013-0128

Storksdieck, Martin (2016). "Critical information literacy as core skill for lifelong STEM learning in the $21^{\text {st }}$ century: reflections on the desirability and feasibility for widespread science media education". Cultural studies of science education, v. 11, pp. 167-182.

https://doi.org/10.1007/s11422-015-9714-4

Street, Brian V. (1995). Literacy in theory and practice. Cambridge: Cambridge University Press. ISBN: 0521289610

Sukovic, Suzana (2014). “iTell: Transliteracy and digital storytelling”. Australian academic and research libraries, v. 45, n. 3, pp. 205-229.

https://doi.org/10.1080/00048623.2014.951114

Tewell, Eamon (2015). "A decade of critical information literacy". Communications in information literacy, v. 9, n. 1, pp. $24-43$. https://doi.org/10.15760/comminfolit.2015.9.1.174

Thomas, Sue; Joseph, Chris; Laccetti, Jess; Mason, Bruce; Mills, Simon; Perril, Simon; Pullinger, Kate (2007). "Transliteracy: Crossing divides". First Monday, v. 12, n. 3.

https://firstmonday.org/ojs/index.php/fm/article/view/2060/1908

Unsworth, Len (2001). Teaching multiliteracies across the curriculum. Buckingham: Open University Press. ISBN: 0335 206050

Wilson, Carolyn; Grizzle, Alton; Tuazon, Ramon; Akyempong, Kwame; Cheung, Chi-Kim (2013). Alfabetización mediática e informacional: curriculum para profesores. Paris: Unesco.

http://unesdoc.unesco.org/images/0021/002160/216099S.pdf

Zhang, Wenxian (2002). “Developing web-enhanced learning for information fluency: A liberal arts college's perspective". Reference \& user services quarterly, v. 41, n. 4, pp. 356-363. 